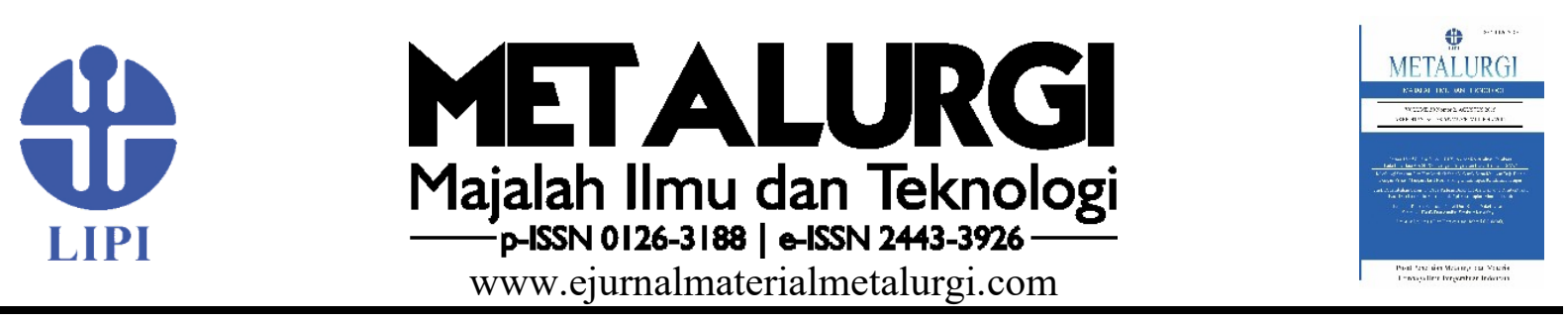

\title{
Pengaruh annealing Terhadap KeKerasan dan STRUKTUR MIKRO BAJA TAHAN KARAT AISI 410-3MO-3Ni
}

\author{
Vinda Puspasari ${ }^{a}$, Mukhlis Agung Prasetyo ${ }^{a}$, Januarius Velix Ta'an Hala ${ }^{b}$, Mochammad \\ Syaiful Anwar ${ }^{\text {, }}$, Satrio Herbirowo ${ }^{\text {, Efendi Mabruri }}{ }^{a}$ \\ ${ }^{a}$ Pusat Penelitian Metalurgi dan Material-LIPI \\ Gedung 470, Kawasan Puspiptek Serpong, Indonesia 15310 \\ ${ }^{\mathrm{b}}$ Sekolah Tinggi Teknik-PLN \\ Jl. Lkr. Luar Barat, RT.1/ RW.1, Duri Kosambi, DKI Jakarta \\ *E-mail: vindapuspa13@gmail.com
}

Masuk Tanggal :07-07-2020, revisi tanggal:21-09-2020, diterima untuk diterbitkan tanggal : 21-10-2020

\begin{abstract}
Abstrak
Baja tahan karat AISI 410 merupakan baja martensitik yang penggunaannya sangat terbatas jika dibandingkan dengan baja tahan karat austenitik dan feritik. Baja martensitik memiliki peranan penting untuk komponen tertentu dikarenakan kombinasi kekuatan, ketangguhan dan ketahanan korosi yang sangat baik. Namun, setelah proses tempa, baja martensitik cenderung mengalami penurunan sifat mekanik dan struktur mikro. Pada penelitian ini, sifat mekanik dan mikrostruktur dari material baja tahan karat AISI 410-3Mo-3Ni hasil tempa setelah mendapat perlakuan panas annealing akan dipelajari. Annealing bertujuan untuk menurunkan kekerasan material dan meningkatkan kehalusan butir dari material. Perlakuan panas annealing dilakukan dengan variasi temperatur dan waktu annealing. Variasi temperatur annealing yaitu 700, 760, 800, 850, dan $900{ }^{\circ} \mathrm{C}$. Variasi waktu annealing yaitu 3 jam dan 6 jam. Pengaruh waktu dan temperatur annealing akan dipelajari terhadap kekerasan yang dianalisis secara statistik dan struktur mikro material baja tahan karat AISI 410-3Mo-3Ni. Kekerasan yang paling optimum adalah baja tahan karat AISI 410-3Mo-3Ni dengan perlakuan panas annealing pada $\mathrm{T}=760{ }^{\circ} \mathrm{C}$ selama 6 jam yaitu 35,9 HRC. Mikrostruktur yang dihasilkan oleh material AISI 410 yang telah mengalami perlakuan panas annealing secara umum yaitu fasa delta ferit, martensit, austenit, dan karbida yang dapat mempengaruhi sifat mekanik.
\end{abstract}

Kata Kunci: Baja tahan karat AISI 410-3Mo-3Ni, annealing, delta ferit, martensit, austenit, karbida

\begin{abstract}
AISI 410-3Mo-3Ni stainless steel is martensitic steel, which is limited in use compared to austenitic and ferritic stainless steel. Martensitic steel plays an important role in specific components due to the combination of hardness, strength, and excellent corrosion resistance. However, after the forging process, martensitic steel appears to decrease in mechanical properties and microstructure. In this study, the mechanical properties and microstructure of the AISI 410 forged after annealing heat treatment will be studied. Annealing helps to minimize material hardness and improve material refinement of grain. The annealing heat treatment is done by adjusting the annealing temperature and time. The temperature ranges are 700,760,800,850, and $900{ }^{\circ} \mathrm{C}$. The annealing time variation is 3 hours and 6 hours. The effect of the annealing time and temperature on the AISI 410 modified material's hardness and microstructure will be studied. The optimum hardness is 35.9 HRC in AISI 410 material with annealing treatment at $760^{\circ} \mathrm{C}$ for 6 hours. The microstructure on that condition showed the delta ferrite, martensite, austenite, and carbide affected the material hardness after annealing.
\end{abstract}

Keywords: AISI 410 stainless steel, annealing, delta ferrite, martensite, austenite, carbide. 


\section{Pendahuluan}

Baja austenik dan baja feritik merupakan contoh baja yang aplikasinya sangat luas dalam industri dan kehidupan sehari-hari dibanding baja martensitik [1]. Baja martensitik dengan kandungan unsur $\mathrm{Cr}$ 12-17\% massa dan kadar karbon $0,15-1 \%$ massa memiliki aplikasi kompetitif dalam industri dikarenakan memiliki kombinasi kekuatan, ketangguhan dan ketahanan korosi yang baik [2]. Baja martensitik dengan kadar karbon yang tinggi sangat rentan mengalami retak saat dilakukan pengelasan maupun proses pembentukan lainnya [3]. BTK (baja tahan karat) martensitik AISI 410 banyak digunakan untuk komponen blade pada aplikasi sistem turbin uap [4].

Kegagalan yang umum terjadi pada komponen ini dikarenakan retakan yang terjadi akibat interaksi antara tegangan yang tinggi dan lingkungan korosif pada sistem turbin [5]. Oleh karena itu, modifikasi unsur kimia dan perubahan struktur mikro baja melalui perlakuan panas diharapkan dapat meminimalisir kegagalan material BTK AISI 410 pada aplikasi turbine blade [6]. Modifikasi unsur kimia pada baja martensitik AISI 410 menjadi AISI 410-3Mo-3Ni dilakukan dengan penambahan unsur Ni dan $\mathrm{Mo}$ yang bertujuan untuk meningkatkan keuletan material, meningkatkan kekuatan tarik, meningkatkan ketahanan korosi pitting dibandingkan dengan material BTK AISI 410 pada umumnya [7].

Perlakuan panas yang biasa dilakukan pada baja martensitik yaitu austenizing, annealing, tempering, dan quenching [8]. Proses manufaktur pada material AISI 410 untuk komponen sudu turbin (turbine blade) umumnya melibatkan proses tempa yang dapat menurunkan sifat mekanik dan struktur mikronya sehingga mudah mengalami aus pada aplikasi sudu turbin. Oleh karena itu, pentingnya memilih proses perlakuan panas untuk mendapatkan sifat mekanik yang optimal [9].

Annealing merupakan perlakuan panas yang cocok untuk menurunkan kekerasan material dan membuat butir bebas dari tegangan sisa pada baja martensitik AISI 410-3Mo-3Ni sehingga dapat meminimalisir kemungkinan aus saat proses penggunaan komponen sudu turbin [10]. Annealing dilakukan dengan memanaskan material pada temperatur tertentu kemudian didinginkan di dalam tungku [11]. Selain itu hal penting dalam proses annealing adalah parameter annealing yang bergantung pada komposisi kimia [12]. Ketika komposisi kimia telah berubah, proses annealing harus disesuaikan dengan perubahan komposisi kimia [13].
Penelitian ini bertujuan untuk mencari optimasi sifat mekanik melalui perolehan nilai kekerasan dan morfologi struktur pada BTK AISI 410-3Ni-3Mo dengan perlakuan panas annealing.

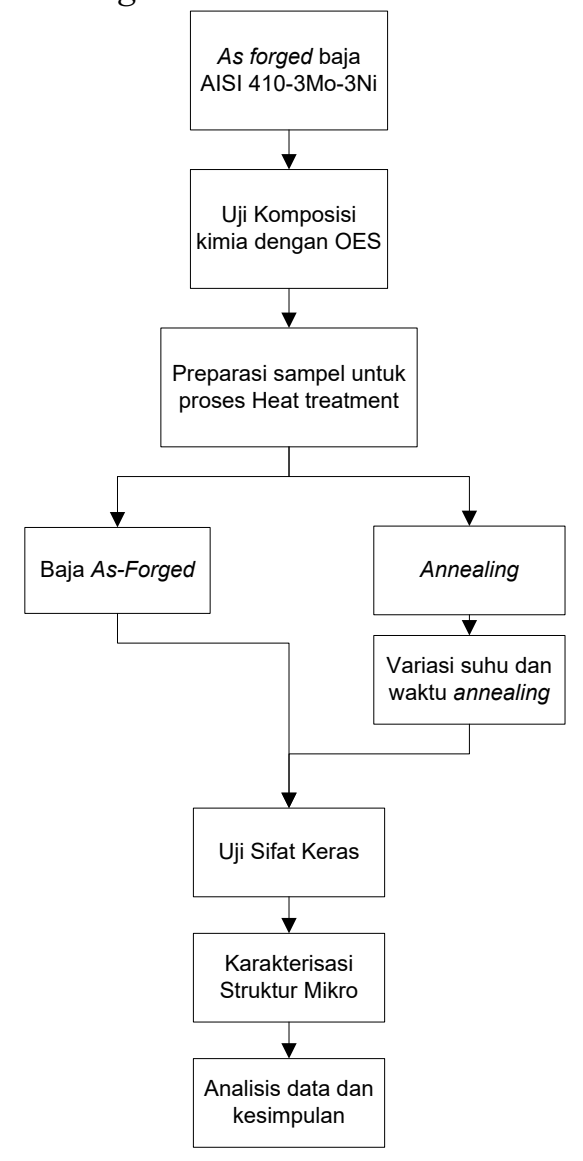

Gambar 1. Diagram alir proses annealing pada BTK AISI $410-3 \mathrm{Mo}-3 \mathrm{Ni}$

\section{Prosedur Percobaan}

Penelitian ini menggunakan BTK (baja tahan karat) AISI 410-3Ni-3Mo hasil proses tempa. BTK AISI 410 terlebih dahulu dikarakterisasi unsur kimianya menggunakan OES (optical emission spectroscopy). Setelah itu, dilakukan pemotongan BTK AISI 410-3Mo-3Ni dengan ukuran $2 \mathrm{~cm} \times 2 \mathrm{~cm}$ untuk kemudian dilakukan perlakuan panas annealing dengan variasi temperatur dan waktu yang digunakan (Gambar $1)$.

Tabel 1. Variasi temperatur dan waktu annealing pada BTK AISI $410-3 \mathrm{Ni}-3 \mathrm{Mo}$

\begin{tabular}{cc}
\hline Nama Sampel & $\begin{array}{c}\text { Variasi T dan waktu } \\
\text { annealing }\end{array}$ \\
\hline A700 3 & $700^{\circ} \mathrm{C}-3$ jam \\
A700 6 & $700^{\circ} \mathrm{C}-6$ jam \\
A760 3 & $760^{\circ} \mathrm{C}-3$ jam \\
A760 6 & $760^{\circ} \mathrm{C}-6$ jam \\
A800 3 & $800^{\circ} \mathrm{C}-3$ jam \\
A800 6 & $800^{\circ} \mathrm{C}-6$ jam \\
\hline
\end{tabular}


Variasi temperatur dan waktu annealing BTK AISI 410-3Ni-3Mo yang digunakan dalam penelitian ini dapat dilihat pada Tabel 1 .

BTK AISI 410-3Ni-3Mo hasil tempa (asforged) juga dilakukan karakterisasi sebagai material pembanding. BTK AISI 410-3Mo-3Ni hasil proses annealing kemudian diuji keras dengan menggunakan metode Rockwell tipe C pada 5 titik, lalu dilakukan analisis secara kuantitatif menggunakan metode ANOVA untuk mengetahui pengaruh variabel yang sangat signifikan terhadap sifat mekanik. Uji normalitas dilakukan terhadap data primer nilai kekerasan sebanyak 5 titik pengujian pada tiap sampel menggunakan metode Kolmogorov-Smirnov dan metode Shapiro-Walk [14]-[15].

Pengujian kekerasan bertujuan untuk mengetahui pengaruh perlakuan panas annealing terhadap kekerasan yang dihasilkan. Pengamatan struktur mikro dilakukan pada material BTK AISI $410-3 \mathrm{Mo}-3 \mathrm{Ni}$ hasil annealing dengan menggunakan mikroskop optik. Spesimen diampelas dengan kertas ampelas grid 600, 800, 1000 dan 1200, kemudian dipoles dengan pasta alumina $5 \mu \mathrm{m}$ hingga $0,1 \mu \mathrm{m}$ sampai permukaan mengkilap. BTK AISI 410-3Mo-3Ni kemudian dietsa dengan menggunakan etsa Kalling reagent (5 $\mathrm{gr} \mathrm{CuCl}_{2}, 100 \mathrm{~mL} \mathrm{HCl}$, dan $100 \mathrm{~mL}$ etanol).

Pengukuran butir dilakukan menggunakan software ImageJ dengan metode line intercept. Pengukuran butir dilakukan pada struktur mikro matriks BTK AISI 410-3Mo-3Ni yang diambil menggunakan mikroskop optik. Perhitungan dilakukan sebanyak 3 kali perhitungan dan diambil nilai rata-rata. Rumus yang digunakan untuk pengukuran ukuran butir yaitu [16]:

$$
\text { Ukuran butir rata }- \text { rata }=\frac{\text { panjang garis }}{\text { jumlah butir }}
$$

\section{Hasil dan Pembahasan \\ 3.1 Pengujian Komposisi Kimia}

Tabel 2 menunjukkan komposisi kimia BTK (baja tahan karat) AISI $410-3 \mathrm{Ni}-3 \mathrm{Mo}$ hasil uji OES (optical emission spectroscopy).

Tabel 2. Komposisi unsur BTK AISI 410-3Mo-3Ni hasil tempa

\begin{tabular}{cccc}
\hline Unsur & \%Massa & Unsur & \%Massa \\
\hline $\mathrm{C}$ & 0,03 & $\mathrm{Cr}$ & 12,8 \\
$\mathrm{~S}$ & 0,012 & $\mathrm{Mo}$ & 0,002 \\
$\mathrm{P}$ & 0,0162 & $\mathrm{Ni}$ & 0,155 \\
$\mathrm{Si}$ & 0,68 & $\mathrm{Fe}$ & Balance \\
$\mathrm{Mn}$ & 0,34 & & \\
\hline
\end{tabular}

BTK ini memiliki kadar karbon yang rendah yaitu $0,03 \%$ serta paduan yang tinggi karena mengandung lebih dari $10 \%$ unsur paduan yang meliputi unsur paduan utama yaitu $\mathrm{Cr}, \mathrm{Mn}$, dan
Ni. Adanya unsur $\mathrm{Cr}$ sebesar $12,8 \%$ dan $\mathrm{Ni}$ sebesar $0,155 \%$ dapat meningkatkan ketahanan korosi BTK AISI 410-3Mo-3Ni.

\subsection{Hasil Uji Keras}

Pengujian kekerasan dilakukan untuk mengetahui pengaruh annealing terhadap kekerasan baja tahan karat AISI 410-3Mo-3Ni.

Tabel 3. Uji normalitas hasil uji keras pada setiap variabel dengan metode Kolgomorov-Smirnov

Kolmogorov-Smirnov

\begin{tabular}{ccrcc}
\hline & Perlakuan & Statistik & df & Sig. \\
Kekerasan & 0,214 & 5 & $0,200^{*}$ \\
& A700 6 & 0,227 & 5 & $0,200^{*}$ \\
& A760 3 & 0,179 & 5 & $0,200^{*}$ \\
A760 6 & 0,221 & 5 & $0,200^{*}$ \\
A800 3 & 0,136 & 5 & $0,200^{*}$ \\
A800 6 & 0,238 & 5 & $0,200^{*}$
\end{tabular}

Note: *. This is a lower bound of the true significance a. Lilliefors Significance Correction

Tabel 3 menunjukkan hasil uji normalitas pada nilai kekerasan pada setiap variabel dengan 5 titik pengujian menggunakan metode KolmogorovSmirnov [14]-[15].

Tabel 4. Uji normalitas hasil uji keras pada setiap variabel dengan metode Shapiro-Wilk

Shapiro-Wilk

\begin{tabular}{ccccc}
\hline & Perlakuan & Statistik & df & Sig. \\
A700 3 & 0,903 & 5 & 0,424 \\
Kekerasan & A700 6 & 0,910 & 5 & 0,468 \\
& A760 3 & 0,962 & 5 & 0,823 \\
& A760 6 & 0,915 & 5 & 0,501 \\
& A800 3 & 0,989 & 5 & 0,976 \\
& A800 6 & 0,900 & 5 & 0,410
\end{tabular}

Note: *. This is a lower bound of the true significance b. Lilliefors Significance Correction

Tabel 4 menunjukkan hasil uji normalitas pada nilai kekerasan pada setiap variabel dengan 5 titik pengujian menggunakan metode ShapiroWilk. Data uji normalitas dari data primer nilai kekerasan menggunakan metode KolmogorovSmirnov dan Shapiro-Wilk [14]-[15] menunjukkan bahwa nilai signifikansi keseluruhan lebih besar dari 0,05 sigma maka 
dapat dikatakan data hasil uji kekerasan terdistribusi normal.

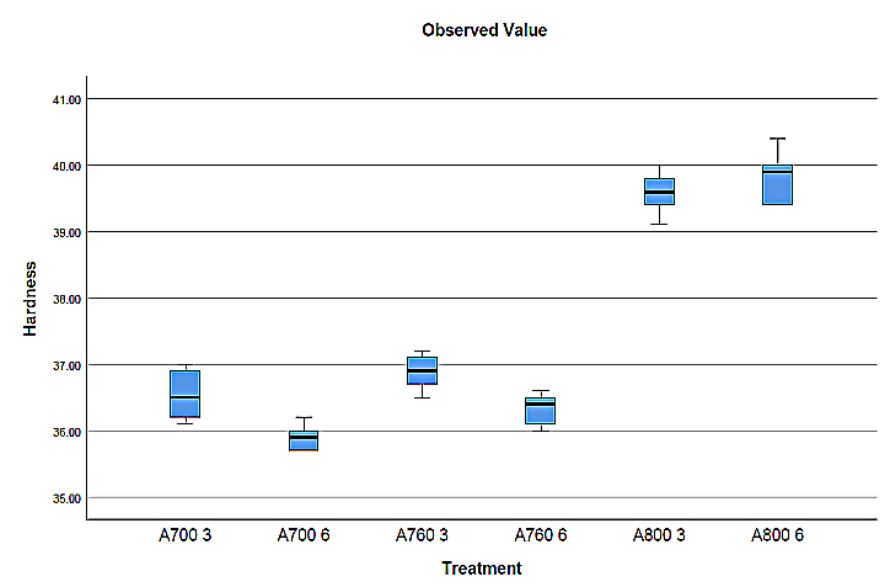

Gambar 2. Grafik kekerasan permukaan BTK AISI 4103Mo-3Ni dengan variasi temperatur dan waktu annealing

Gambar 2 menunjukkan nilai kekerasan tertinggi dicapai oleh BTK AISI 410-3Mo-3Ni dengan kode A800 6 yaitu sebesar 40,4 HRC. Semakin rendah temperatur annealing, material semakin ulet yang terlihat dari grafik kekerasan yang semakin menurun. Kekerasan paling rendah didapatkan pada BTK AISI 410-3Mo-3Ni dengan kode A700 6 yaitu sebesar 35,9 HRC. Kekerasan ini sudah optimal jika dibanding kekerasan BTK AISI 410-3Mo-3Ni as-forged yang memiliki nilai 51,56 HRC. Annealing dilakukan untuk mendapatkan nilai kekerasan material yang optimal sesuai standar baja konstruksi karena dengan kekerasan yang menurun, maka sifat keuletan akan meningkat seiring dengan transformasi strukturnya [17].

Sebelum melakukan analisis one-way ANOVA, susunan hipotesa untuk model ini yaitu:

-Hipotesa awal (H0) = ditetapkan faktor berpengaruh signifikan terhadap kekerasan

-Hipotesis alternatif $(\mathrm{H} 1)=$ ditetapkan penolakan terhadap $\mathrm{H} 0$

-H0 ditolak jika $\mathrm{P}>\alpha$ atau apabila nilai $\mathrm{F}$ melebihi nilai $\mathrm{F} \alpha$, df-num, df-den

Tabel 4. Analisis kuantitatif one-way ANOVA dari hasil uji kekerasan pada setiap variabel

\begin{tabular}{llllll}
\hline Kekerasan & Jumlah & df & $\begin{array}{l}\text { Rata- } \\
\text { rata }\end{array}$ & F & Sig. \\
\hline $\begin{array}{l}\text { Antar } \\
\text { grup }\end{array}$ & 74,835 & 5 & 14,967 & 135,857 & 0,00001 \\
$\begin{array}{l}\text { Dalam } \\
\text { grup }\end{array}$ & 2,644 & 24 & 0,110 & & \\
Total & 77,479 & 29 & & & \\
\hline
\end{tabular}

Dari hasil analisis data kekerasan menggunakan one-way ANOVA dapat dilihat bahwa nilai Sig $<\alpha(0,05)$ yang berarti membuktikan hipotesis awal (H0) dapat diterima. Dengan demikian variabel perlakuan panas mencakup temperatur dan waktu annealing berpengaruh secara signifikan terhadap kekerasan BTK AISI 410-3Mo-3Ni.

\subsection{Analisis Struktur Mikro}

Struktur mikro yang dihasilkan setelah proses annealing dapat mempengaruhi sifat mekanik BTK AISI 410-3Ni-3Mo.

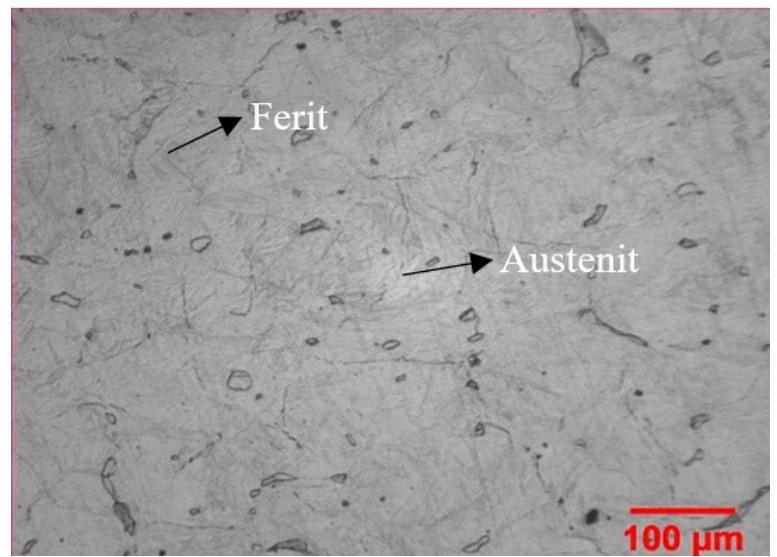

Gambar 3. Struktur mikro BTK AISI 410-3Mo-3Ni hasil tempa (as-forged). Etsa Kalling reagent

Gambar 3 menunjukkan struktur mikro BTK AISI 410-3Mo-3Ni hasil tempa tanpa perlakuan annealing dengan fasa yang terbentu adalah fasa ferit dan fasa austenit.

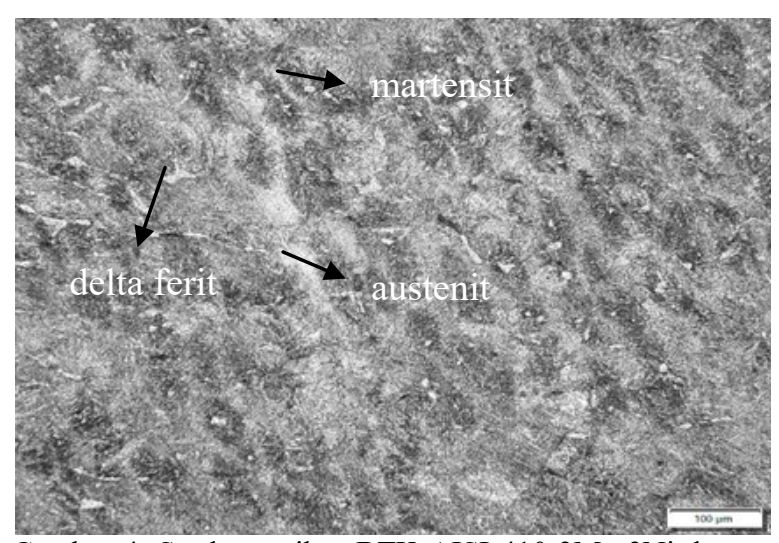

Gambar 4. Struktur mikro BTK AISI 410-3Mo-3Ni dengan mikroskop optik setelah annealing pada $\mathrm{T}=700{ }^{\circ} \mathrm{C}$ selama 3 jam. Etsa Kalling reagent

Secara umum fasa BTK AISI 410-3Mo-3Ni yaitu delta ferit, austenit, martesit, dan karbida [18]. Gambat 4 menunjukkan fasa delta ferit yang berbentuk seperti pulau kecil berwarna putih yang tersebar merata hampir di seluruh area dengan luas area rata-rata yaitu $161 \mu \mathrm{m}^{2}$. Fasa karbida ditunjukkan oleh titik berwarna hitam, dan fasa fine martensite yang terlihat seperti jarum berwarna hitam. Karbida $\mathrm{Cr}_{23} \mathrm{C}_{6}$ terjadi 
karena proses solution-annealed pada temperatur $500-900{ }^{\circ} \mathrm{C}[19]$.

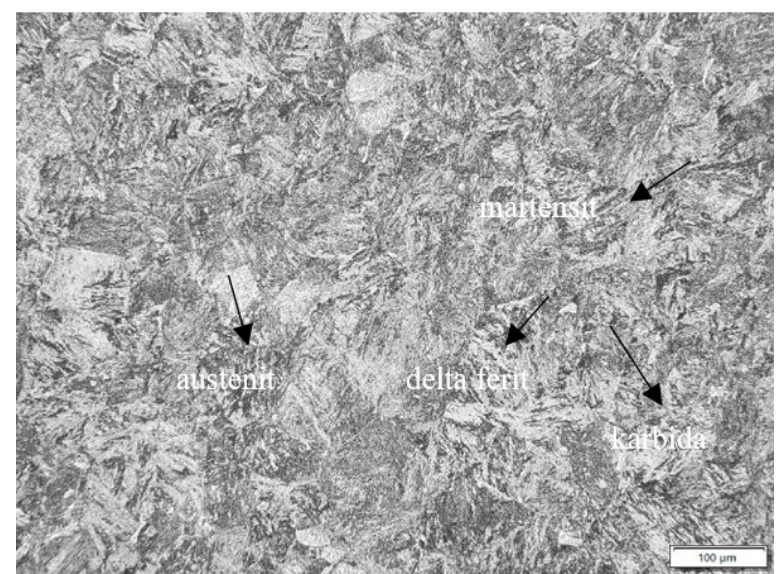

Gambar 5. Struktur mikro BTK AISI 410-3Mo-3Ni dengan mikroskop optik setelah annealing pada $\mathrm{T}=700{ }^{\circ} \mathrm{C}$ selama 6 jam. Etsa Kalling reagent

Gambar 5 menunjukkan butir matriks memiliki ukuran yang lebih besar dibanding Gambar 4 yaitu $42 \mu \mathrm{m}$ (dapat dilihat pada Gambar 10). Fasa austenit terlihat lebih jelas dibanding Gambar 4. Fasa martensit terlihat lebih jelas berbentuk lath berwarna hitam. Adanya fasa delta ferit yang memiliki butir besar dengan luas area rata-rata yaitu $236,6 \mu \mathrm{m}^{2}$ mengakibatkan BTK AISI 410-3Mo-3Ni menurun kekerasannya [6].

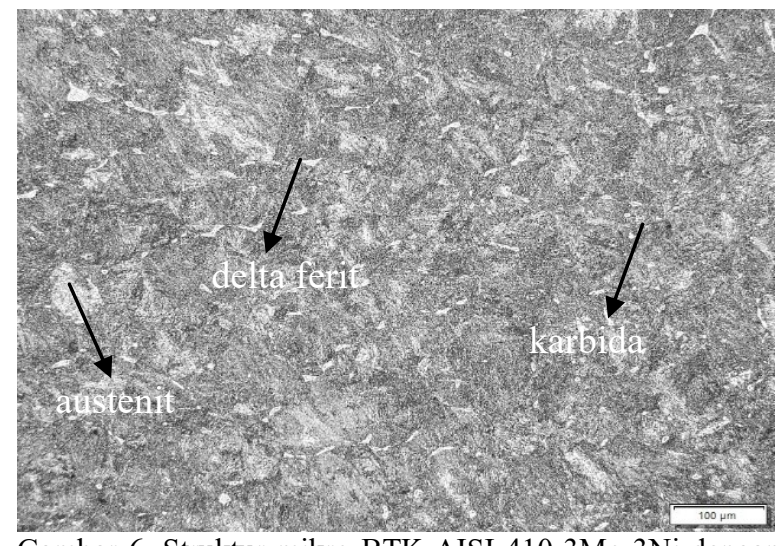

Gambar 6. Struktur mikro BTK AISI 410-3Mo-3Ni dengan mikroskop optik setelah annealing pada $\mathrm{T}=760^{\circ} \mathrm{C}$ selama 3 jam. Etsa Kalling reagent

Gambar 6 menunjukkan fasa delta ferit yang terlihat lebih jelas namun lebih kecil dibandingkan fasa yang terbentuk pada BTK AISI 410-3Mo-3Ni setelah annealing pada $\mathrm{T}=$ $700{ }^{\circ} \mathrm{C}$, luas area rata-rata fasa delta ferit yaitu $138,7 \mu \mathrm{m}^{2}$ yang tersebar merata hampir di seluruh area. Fasa delta ferit dapat dilihat seperti pulau kecil yang berwarna terang membentuk struktur spheroidal. Fasa delta ferit memiliki sifat memicu nukleasi dan penggabungan microvoid dan dapat menimbulkan fracture pada material yang terekspos temperatur tinggi [20]. Oleh karena itu, fasa delta ferit sangat dibatasi jumlahnya agar sifat mekanik dari material dapat dikontrol dengan baik [21].

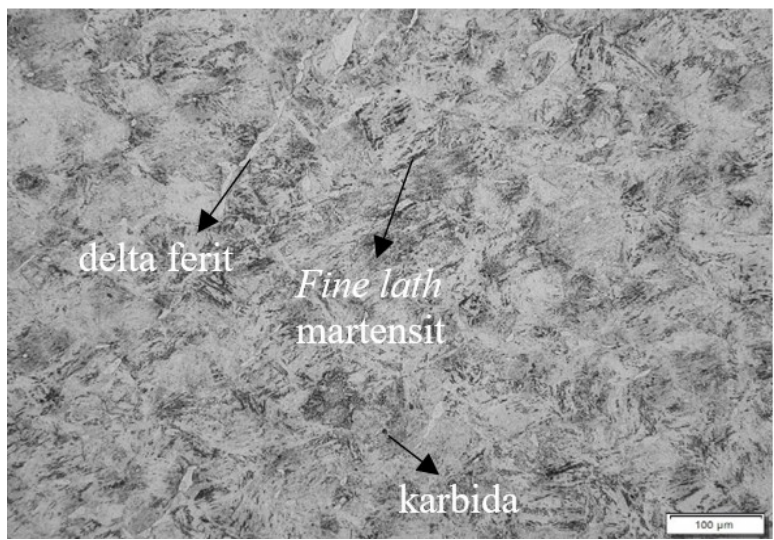

Gambar 7. Struktur mikro BTK AISI 410-3Mo-3Ni dengan mikroskop optik setelah annealing pada $760{ }^{\circ} \mathrm{C}$ selama 6 jam. Etsa Kalling reagent

Martensit terlihat lebih jelas pada Gambar 7 berbentuk fine lath martensite serta fasa delta ferit yang terlihat berbentuk struktur platelet dan jumlahnya lebih sedikit dibanding Gambar 6. Hal ini dikarenakan berubahnya struktur spheroidal dari delta ferit menjadi struktur platelet dan jumlahnya semakin berkurang karena fasa ini menghilang dan larut seiring dengan waktu holding anneling yang meningkat [22]. Selain itu, peningkatan waktu annealing juga meningkatkan ukuran butir yang ditunjukkan pada Gambar 10 . BTK AISI $410-3 \mathrm{Mo}-3 \mathrm{Ni}$ yang diproses annealing pada temperatur $760{ }^{\circ} \mathrm{C}$ selama 6 jam memiliki butir yang lebih besar dibanding BTK AISI $410-3 \mathrm{Mo}-3 \mathrm{Ni}$ yang diproses annealing pada temperatur $760{ }^{\circ} \mathrm{C}$ selama 3 jam.

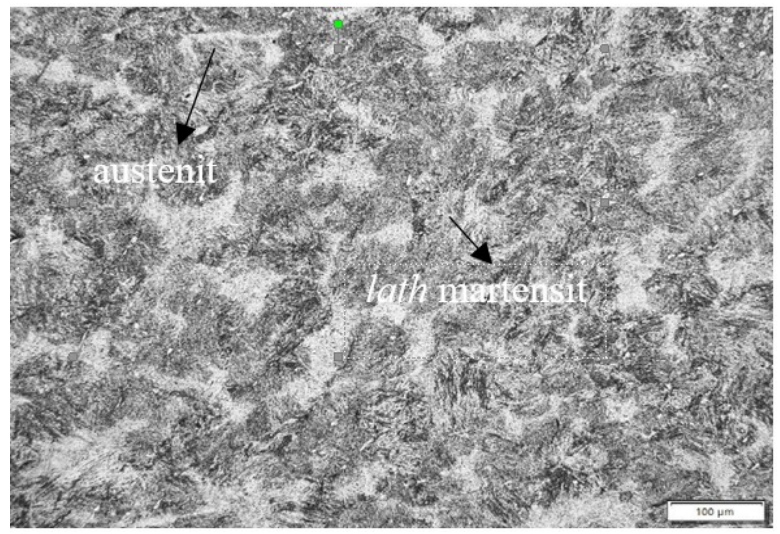

Gambar 8. Struktur mikro BTK AISI 410-3Mo-3Ni dengan mikroskop optik setelah annealing pada $800{ }^{\circ} \mathrm{C}$ selama 3 jam. Etsa Kalling reagent

Gambar 8 menunjukkan fasa delta ferit, lath martensit, dan fine martensit serta karbida. Terlihat fasa delta ferit semakin berkurang dan fasa lath martensit semakin bertambah. Hal ini juga ditunjukkan dengan peningkatan kekerasan. 


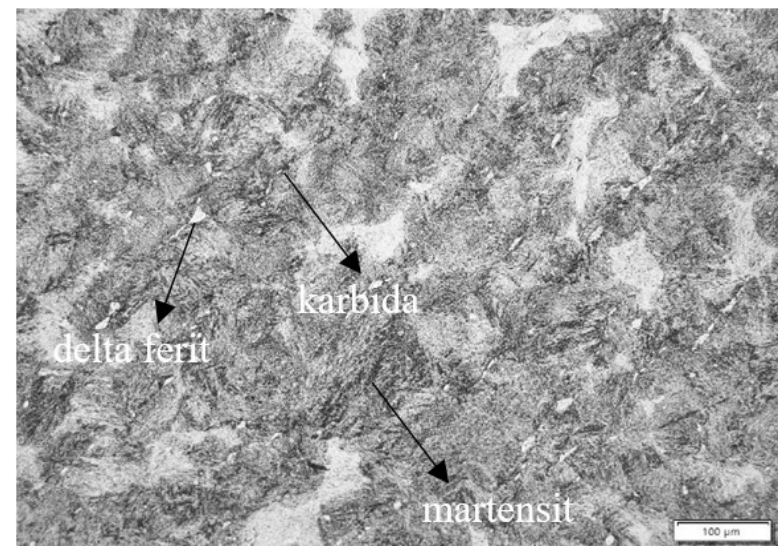

Gambar 9. Struktur mikro BTK AISI 410-3Mo-3Ni dengan mikroskop optik setelah annealing pada $800{ }^{\circ} \mathrm{C}$ selama 6 jam. Etsa Kalling reagent

Gambar 9 menunjukkan fasa delta ferit yang terlihat sangat sedikit dikarenakan pembentukan fasa karbida sangat dominan dan fasa delta ferit juga terlarut seiring peningkatan temperatur annealing [22]. Fasa karbida terbentuk pada temperatur $500-950{ }^{\circ} \mathrm{C}$ dan laju pembentukan fasa karbida semakin cepat seiring penambahan temperatur [23]. Karbida akan larut pada temperatur di atas $1100{ }^{\circ} \mathrm{C}$. Karbida membuat kekerasan BTK AISI 410-3Mo-3Ni meningkat. Hal ini yang menyebabkan kekerasan BTK AISI 410-3Mo-3Ni pada temperatur dan waktu annealing ini paling tinggi di antara baja dengan perlakuan panas annealing lainnya.

\subsection{Analisa Pengaruh Temperatur dan Waktu Annealing terhadap Ukuran Butir Matriks}

Gambar 10 menunjukkan pengaruh perlakuan panas annealing terhadap ukuran butir yang dihasilkan pada material BTK AISI 4103Mo-3Ni.

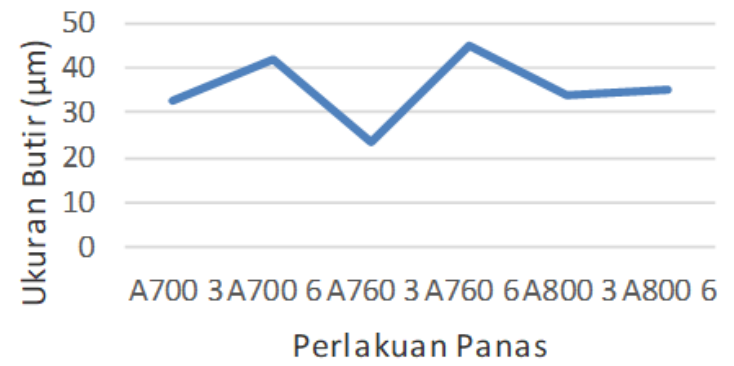

Gambar 10. Pengaruh perlakuan panas annealing terhadap ukuran butir pada material BTK AISI $410-3 \mathrm{Mo}-3 \mathrm{Ni}$

Ukuran butir pada BTK AISI 410-3Mo-3Ni dengan kode perlakuan A7006 memiliki nilai yang lebih besar dibanding material dengan kode perlakuan A7003. Hal ini membuat nilai kekerasannya lebih rendah dari baja AISI 4103Mo-3Ni kode perlakuan A700 3 dikarenakan adanya fasa delta ferit yang berukuran lebih besar (dapat dilihat pada Gambar 5) sehingga menurunkan nilai kekerasan.

Dapat dilihat bahwa ukuran butir yang paling besar senilai $44,6 \mu \mathrm{m}$ adalah BTK AISI 410 dengan kode perlakuan A760 6 menggunakan perlakuan panas annealing pada temperatur $760{ }^{\circ} \mathrm{C}$ selama 6 jam. Kekerasan material ini yaitu sebesar 36,32 HRC. Kekerasan yang tinggi dipengaruhi oleh banyaknya fasa fine lath martensit dan minimnya fasa delta ferit pada material ini. Ukuran butir yang paling kecil yaitu BTK AISI 410 dengan kode perlakuan A760 3 yaitu sebesar $23,44 \mu \mathrm{m}$ yang memiliki kekerasan sebesar 36,88 HRC. Hal ini menunjukkan semakin kecil ukuran butir maka nilai kekerasan semakin besar dengan perlakuan panas pada temperatur yang sama namun waktu annealing berbeda.

BTK AISI $410-3 \mathrm{Mo}-3 \mathrm{Ni}$ dengan variasi waktu annealing selama 6 jam cenderung memiliki ukuran butir yang lebih besar dibanding waktu annealing selama 3 jam. Hal ini dikarenakan annealing berfungsi untuk membuat butir menjadi lebih besar dan bebas dari tegangan sisa sehingga membuat nilai kekerasannya lebih rendah.

\section{KeSIMPULAN}

Berdasarkan hasil penelitian pengaruh temperatur dan waktu annealing terhadap sifat mekanik dan struktur mikro BTK (baja tahan karat) AISI 410-3Mo-3Ni diperoleh hasil bahwa nilai kekerasan tertinggi terjadi pada BTK AISI410-3Mo-3Ni yang memperoleh perlakuan panas annealing $800{ }^{\circ} \mathrm{C}$ selama 6 jam (A800 6) sebesar 40,4 HRC. Kekerasan paling rendah didapatkan pada BTK AISI 410-3Mo-3Ni dengan perlakuan annealing $700{ }^{\circ} \mathrm{C}$ selama 6 jam (A700 6) yaitu sebesar 35,9 HRC. Hasil analisis statistik pada data uji kekerasan menunjukkan nilai kekerasan terdistribusi normal dan analisa one-way ANOVA menunjukkan hipotesis awal (H0) dapat diterima sehingga variasi temperatur dan waktu anneling berpengaruh signifikan. Struktur mikro yang terbentuk pada BTK AISI $410-3 \mathrm{Mo}-3 \mathrm{Ni}$ dengan nilai kekerasan tertinggi adalah sedikit fasa delta ferit, dengan dominasi fasa martensit lath, fine martensit serta karbida.

\section{UCAPAN TERIMA KASIH}

Penulis mengucapkan terima kasih kepada Pusat Penelitian Metalurgi dan Material-LIPI yang telah mendanai penelitian ini melalui DIPA tahun 2019. Penulis juga mengucapkan terima kasih kepada semua pihak yang telah bekerja sama dari tim peneliti maupun teknisi Baja Unggul 
Nasional Berbasis Laterit. Kontributor utama dalam makalah ilmiah ini adalah Vinda Puspasari.

\section{Daftar Pustaka}

[1] R. Dwisaputro, M. S. Anwar, Rusnaldy, dan E. Mabruri, "Pengaruh perlakuan panas baja tahan karat martensitik AISI 410 terhadap struktur mikro dan ketahanan korosi," Maj. Metal., vol. 33, no. 1, pp. 19-26, 2018. Doi: 10.14203/metalurgi.v33i1.332.

[2] J. C. Ezechidelu, S. O. Enibe, D. O. Obikwelu, P. S. Nnamchi, dan C. S. Obayi, "Effect of heat treatment on the microstructure and mechanical properties of a welded AISI 410 martensitic stainless steel," Int. Adv. Res. J. Sci. Eng. Technol., vol. 3, no. 4, pp. 6-12, 2016. Doi: 10.17148/IARJSET.2016.3402.

[3] H. M. Mohammad dan F. S. Ahmed, "Effects of heat treatment and surface finish on the crevice corrosion resistance of martensitic stainless steel," Basrah J. Eng. Sci., vol. 17, no. 2, pp. 9-17, 2017.

[4] L. Cramer, M. Steinbacher, H. W. Zoch, I. Bösing, dan J. Thöming, "Influence of heat treatment on the microstructure and corrosion resistance of martensitic stainless steel," $A I P A d v$., vol. 9, p. 065317, 2019. Doi: 10.1063/1.5094615.

[5] M. A. Prasetyo, V. Puspasari, M. S. Anwar, A. Nikitasari, and E. Mabruri, "Mechanical properties of modified cast martensitic stainless steel CA6NM with addition of molybdenum and nitrogen," in AIP Conference Proceeding, 2020, no. 060001. doi: 10.1063/5.0004773.

[6] E. Mabruri, M. S. Anwar, S. Prifiharni, T. B. Romijarso, dan B. Adjiantoro, "Pengaruh Mo dan Ni terhadap struktur mikro dan kekerasan baja tahan karat martensitik 13 Cr," Maj. Metal., vol. 30, no. 3, pp. 133-140, 2015. Doi : 10.14203/metalurgi.v30i3.73.

[7] A. Nikitasari, M. A. Prasetyo, R. Riastuti, dan E. Mabruri, "Pitting corrosion resistance of $\mathrm{CA} 6 \mathrm{NM}$ as geothermal turbine blade material in simulated artificial geothermal brine," in IOP Conference Series: Materials Science and Engineering 514, 2019. Doi: 10.1088/1757-899X/541/1/012016.

[8] G. Chakraboty, C. R. Das, K. S. Albert, A. K. Bhaduri, dan V. T. Paul, "Study on tempering behaviour of AISI 410 stainless steel," Mater. Charact., 2014. Doi: 10.1016/j.matchar.2014.12.015.

[9] M. C. Tsai, C. S. Chiou, J. S. Du, dan J. R. Yang, "Phase transformation in AISI 410 stainless steel," Mater. Sci. Eng. A, vol. 332, pp. 1-10, 2002. Doi: 10.1016/S09215093(01)01710-5.

[10] I. Calliari, M. Zanesco, M. Dabala, K. Brunelli, dan E. Ramous, "Investigation of microstructure and properties of a $\mathrm{Ni}-$ Mo martensitic stainless steel," Mater. Des., vol. 29, pp. 246-250, 2008. Doi: 10.1016/j.matdes.2006.11.020.

[11] P. Rosemann, N. Kauss, C. Mu, dan T. Halle, "Influence of solution annealing temperature and cooling medium on microstructure, hardness and corrosion resistance of martensitic stainless steel X46Cr13," Mater. Corros., vol. 66, no. 10, pp. 1068-1076, 2015. Doi: $10.1002 /$ maco.201408081.

[12] E. Mabruri, Z. A Syahlan, S. Prifiharni, dan M. S. Anwar, "Influence of austenitizing heat treatment on the properties of the tempered type 410-1Mo stainless steel," in IOP Conference Series: Materias Science and Engineering, pp. 18, 2017. Doi: 10.1088/1757$899 X / 202 / 1 / 012085$.

[13] A. S. Apriani, M. S. Anwar, Rusnaldy, dan E. Mabruri, "Peningkatan ketahanan aus pada baja tahan karat martensitik $13 \mathrm{Cr}$ AISI 410 setelah proses austenisasi dan tempering," Maj. Metal., vol. V, no. 3, pp. 115-122, 2017.

[14] L. Monostori, V. D. Majstorovic, S. J. Hu, dan D. Djurdjanovic, Lecturer Notes in Mechanical Engineering. 2019.

[15] A. Królicka, K. Radwański, A. Ambroziak, dan A. Żak, "Analysis of grain growth and morphology of bainite in medium-carbon spring steel," Mater. Sci. Eng. A, vol. 768, no. July, 2019. Doi: 10.1016/j.msea.2019.138446.

[16] ASTM E112-12, "Standard Test Methods for Determining Average Grain Size," in ASTM International, 2012.

[17] M. Y. Hasbi, D. P. Malau, dan B. Adjiantoro, "Pengaruh variasi reduksi terhadap kekerasan dan struktur mikro baja laterit melalui pengerolan panas," in Seminar Nasional Sains dan Teknologi, pp. 1-8, 2016.

[18] M. Šebek, P. Horňak, S. Longauer, P. Zimovčák, dan P. Záhumenský, "Influence of annealing process on microstructure and mechanical properties of C-Mn dual phase steel," Kov. Mater, 
vol. 53, pp. 341-348, 2015. Doi: 10.4149/km 20155341.

[19] G. F. V. Voort, G. M. Lucas, dan Buehler, "Metallography and microstructures of stainless steels and maraging steels," in ASM Handbook, Volume 9: Metallography and Microstructure, pp. 683-685, 2004.

[20] M. Mirzaee, A. Momeni, N. Aieni, dan H. Keshmiri, "Effect of quenching and tempering on microstructure and mechanical properties of 410 and $410 \mathrm{Ni}$ martensitic stainless steels," J. Mater. Res., vol. 32, no. 3, pp. 687-696, 2017. Doi: $10.1557 / j \mathrm{mr} .2016 .485$.

[21] L. Fu, Z. Li, H. Wang, dan A. Shan, "Luders-like deformation induced by delta-ferrite-assisted martensitic transformation in a dual-phase highmanganese steel," Scr. Mater., vol. 67, no. 3, pp. 297-300, 2012. Doi: 10.1016/j.scriptamat.2012.05.010.

[22] P. Wang, S. P. Lu, N. M. Xiao, D. Z. Li, dan Y. Y. Li, "Effect of delta ferrite on impact properties of low carbon $13 \mathrm{Cr}-$ 4Ni martensitic stainless steel," Mater. Sci. Eng. A, vol. 527, no. 13-14, pp. 32103216, 2010. Doi: 10.1016/j.msea.2010.01.085.

[23] A. F. Padilha, R. Lesley, dan P. R. Rios, "Stainless steel heat treatment," in Materials Sciences and Technology, no. January, Taylor and Francis Group, pp. 706-707, 2007. 